\title{
Fauna e flora do Aeroporto de Palmas (TO): um alerta para a sua conservação
}

\section{Fauna and flora of Palmas Airport (TO Brazil): an alert for its conservation}

\author{
Mariana Carla de Almeida, Kellen Lagares Ferreira Silva, \\ Tulio Dornas, Fernanda Brito de Abreu, Carla Simone Seibert
}

\begin{abstract}
RESUMO: O Aeroporto Brigadeiro Lysias Rodrigues, em Palmas/TO, foi implantado em 2001 em umas das maiores áreas aeroportuárias patrimoniais do Brasil, composta em sua maioria por áreas verdes onde habitam dezenas de espécies de flora e fauna. Apesar do impacto inicial, com a construção do aeroporto, nenhum estudo foi realizado para avaliar se a fauna e flora foram conservadas, com a sua operacionalidade, ao longo dos últimos anos. Portanto, objetivou-se neste trabalho verificar as condições de conservação da fauna e flora da área patrimonial do Aeroporto, com vistas ao turismo ecológico. A conservação da flora foi avaliada por sensoriamento remoto e a fauna por busca ativa e pesquisa documental, nos registros do aeroporto e do CENIPA, para os anos de 2014, 2016 e 2018. Os resultados demonstraram conservação da flora na área patrimonial do aeroporto e diversos representantes da fauna, contudo ainda sob riscos de impactos futuros. Como alerta, destaca-se a necessidade da área aeroportuária de Palmas desenvolver atividades ecoturísticas, possibilitando maior contato da população com esse ambiente natural, com vistas a sua conservação.
\end{abstract}

PALAVRAS CHAVE: Aeroporto; Conservação; Flora; Fauna; Ecoturismo.

\section{ABSTRACT}

The Brigadeiro Lysias Rodrigues Airport, in Palmas / TO, was established in 2001 in one of the largest heritage areas of Brazil, composed mainly of green areas where dozens of species of flora and fauna live. Despite the initial impact, with the construction of the airport, no study was carried out to evaluate if fauna and flora were conserved, with their operation, over the last years. Therefore, the objective of this work was to verify the conservation conditions of the fauna and flora of the patrimonial area of the Airport, with a view to ecological tourism. The conservation of the flora was evaluated by remote sensing and the fauna by active search and documentary research, in the records of the airport and CENIPA, for the years 2014, 2016 and 2018. The results demonstrated the conservation of flora in the patrimonial area of the airport and several representatives of the fauna, yet still at risk of future impacts. As an alert, we highlight the need for the airport area of Palmas to develop ecotourism activities, allowing greater contact of the population with this natural environment, with a view to its conservation.

KEYWORDS: Airport; Conservation; Flora; Fauna; Ecotourism. 


\section{Introdução}

A intervenção humana vem modificando os habitats, o que contribui com a poluição, introduz novos predadores e interfere nos ecossistemas naturais, dando lugar aos ambientes antropizados. Essa transformação do habitat, de natural à antrópico, com a depreciação dos nichos originais, modifica diretamente a distribuição e a abundância das espécies (GARAFFA et al., 2009). Nesse contexto, empreendimentos como rodovias, ferrovias, portos, usinas de geração de eletricidade, complexos industriais e aeroportos são considerados modificadores do meio ambiente, pois geram significativos impactos ambientais (CONAMA, 1986).

Em relação aos aeroportos, eles causam impactos ambientais desde a sua construção até a sua operacionalidade cotidiana, como a produção de ruídos, geração de resíduos sólidos, emissões de gases na atmosfera, impactos nos recursos hídricos, no solo, na flora, na fauna, dentre outros. (GUEDES et al., 2010; SILVA, 2014). Em decorrência dessas modificações os aeroportos podem fornecer novos nichos como abrigos, locais de nidificação e variedade de itens alimentares como grama, hortaliças, insetos, pequenos mamíferos e carniça, o que torna 0 ambiente atrativo, principalmente para as aves, grupo de maior risco de colisão com as aeronaves (GALVÃO; ALVAREZ, 2010; GUEDES et al., 2010; SOUSA; LIMA; ALBUQUERQUE, 2011; RUIZ-ESPARZA, et al. 2014; HAUPTFLEISCH et al., 2015). Nesse cenário, práticas adequadas devem ser adotadas para minimizar estes impactos (DONATO, 2008; SOUZA; GOMES; CARVALHO, 2016).

Isso é reforçado por Leite (2012), que evidencia a necessidade de se fazer a 'ecologia da cidade', considerando a natureza não mais como um sistema separado da cidade. Ele define esse conceito como ecologia urbana ou eco-urbanismo, cujo viés é discutir acerca das perspectivas de que as tecnologias verdes, aliadas à gestão inteligente do território, estão abrindo, no desenvolvimento urbano de novos territórios, visando tornar áreas mais sustentáveis, bem como, também cidades inteiras verdes. Para tanto, Sachs (2009, p.60) afirma da necessidade de uma combinação viável entre economia e ecologia, pois as ciências naturais podem descrever o que é preciso para um mundo sustentável, mas compete às ciências sociais a articulação das estratégias de transição rumo a este caminho.

Entretanto, existe uma questão ainda maior a ser considerada, que é o fato da necessidade de formação de pessoas que se importam com a natureza, pois, caso contrário, tendem a perder as experiências mais significativas da vida, que as conexões com o ambiente natural podem proporcionar (BEATLEY, 2011), uma vez que "somos parte dela [natureza], e nossa qualidade de vida depende da qualidade dessa relação, de como percebemos a sua importância, de como convivemos com ela" (HERZOG, 2013, p. 109).

O contato com a natureza é uma necessidade inata do ser humano e tem sido introduzida por meio do conceito denominado de biofilia (WILSON, 
1986), entendida como um 'complexo de regras de aprendizagem' desenvolvido sobre milhares de anos de evolução e interação humano-meio ambiente. Mas para que essa conexão se perpetue, ainda que a biofilia seja uma tendência genética, é necessário reforçar o contato com a natureza através de uma constante 'inserção' com meio natural, isto é, um conjunto rico e diversificado de experiências exploratórias em ambiente natural, que reforce estas conexões (BEATLEY, 2011).

Portanto, sob uma visão biofílica, as cidades são espaços fundamentalmente ecológicos, isto é, ecossistemas repletos de árvores e outros tipos de vegetação que compõem uma floresta urbana, abrigam pássaros, insetos, pequenos mamíferos, diversos habitats ecológicos e muito mais. Uma cidade biofílica, portanto, é aquela que possui natureza abundante, visa reparar e restaurar, bem como inserir criativamente a natureza onde for possível, permitindo que seus habitantes usufruam de riquezas biológicas e se preocupem com a natureza, trabalhando a seu favor, a nível local e global (BEATLEY, 2011). São biofílicas as áreas urbanas que conservam e protegem a natureza em suas várias formas, incluindo fauna e flora, e promovem os contatos diários de seus cidadãos com o ambiente natural em seus bairros. Mas essas ações, no entanto, segundo Chacel (2001), só se tornam possíveis de serem realizadas quando há uma integração de equipes multi e interdisciplinares, que se envolvam com a paisagem a planejar, pois no seu planejamento integrado devem ser considerados todos os elementos geobiofísicos ${ }^{1}$ e as estruturas socioeconômicas que a compõem.

O Aeroporto Brigadeiro Lysias Rodrigues e neste trabalho também chamado de Aeroporto de Palmas, possui uma das maiores áreas patrimoniais aeroportuárias do país. Em seus limites existem extensa cobertura vegetal nativa, cujas fitofisionomias são características do bioma Cerrado (RIBEIRO; WALTER, 2008). Esta expressiva área, nos limites do aeroporto de Palmas, está inserida na área urbana da cidade, representa um importante remanescente da vegetação nativa do bioma Cerrado em nível municipal, sendo, portanto, estratégica em âmbito regional para conservação da flora e fauna, assim como, na manutenção de serviços ecológicos e ecossistêmicos locais. Portanto, este trabalho objetivou verificar as condições de conservação da fauna e flora da área patrimonial do Aeroporto Brigadeiro Lysias Rodrigues, em Palmas/TO, com vistas ao turismo ecológico.

\section{Delimitação da área do estudo}

O Aeroporto Brigadeiro Lysias Rodrigues está localizado na cidade de Palmas, estado do Tocantins, às margens do lago formado pela Usina Hidrelétrica Luis Eduardo Magalhães ou Lago de Palmas. Construído a partir de 1999, foi inaugurado em 2001 com uma área patrimonial de aproximadamente 2.375 (dois mil, trezentos e setenta e cinco) hectares (INFRAERO, 2018 - Figura 1). 




Figura 1: Aeroporto Brigadeiro Lysias Rodrigues em Palmas/TO, Brasil. Linha vermelha sítio aeroportuário; Verde - Área Patrimonial do aeroporto; Azul - Área Operacional.

Figure 1: Brigadeiro Lysias Rodrigues Airport in Palmas/TO, Brazil. Red line - airport site; Green - Airport Patrimonial Area; Blue - Operational Area.

Fonte: Google (2017).

Source: Google (2017).

Existe uma área exclusiva, na extensão da área patrimonial, reservada para as atividades aéreas, denominada de área operacional (azul). A área operacional possui um total de 144,3 hectares (cento e quarenta e quatro hectares). Todo o restante é composto basicamente por área de vegetação nativa, inicialmente reservada para a ampliação futura do aeroporto, sendo coberta por vegetação típica do Cerrado. A administração e conservação da área patrimonial é realizada pela Empresa Pública Federal de Infraestrutura Aeroportuária (INFRAERO, 2018). 


\section{Materiais e métodos}

A coleta de dados sobre elementos da fauna ocorreu por meio de pesquisas bibliográficas com a busca e análise de fontes secundárias, como registros, relatórios organizacionais, e por meio de levantamento de dados in loco, junto aos limites do aeroporto. para análise da flora, imagens de satélite, imagens de satélites foram obtidas para os anos 2014, 2016 e 2018 com intuito de verificar possíveis mudanças na cobertura e uso do solo da região do aeroporto.

Desta forma, metodologicamente o estudo foi dividido em duas etapas. Na primeira etapa foi utilizado o sensoriamento remoto para avaliar alterações na cobertura e uso do solo na área aeroportuária de Palmas. $\mathrm{Na}$ segunda etapa, foram coletados, por meio da pesquisa documental os registros de colisão, quase-colisão e avistamento da fauna do aeroporto de Palmas, no Centro de Investigação e Prevenção de Acidentes Aeronáuticos (CENIPA), e registros junto à administradora do aeroporto com o objetivo de identificar impactos à fauna, assim como, espécies de vertebrados existentes no sítio aeroportuário.

\section{Análise da vegetação por sensoriamento remoto}

Para a análise da vegetação foram coletadas imagens do catálogo do Instituto Nacional de Pesquisas Espaciais - INPE, advindas dos satélites Landsat 8, Sensor OLI, onde ele possui resolução espacial de $30 \mathrm{~m}$. As cenas escolhidas foram das datas 10/10/2014, 16/10/2016, 23/10/2018, órbita ponto 222/067, das bandas espectrais 3, 4, 5 e 6 .

A escolha das datas para a coleta das imagens se deu em virtude da menor cobertura de nuvens nessa época, evidenciando a vegetação natural. Além disso, o período foi definido em razão da disponibilidade e da resolução temporal das imagens, que se refere à frequência de passagem do sensor em uma mesma região e em um determinado intervalo de tempo, considerando as características orbitais da plataforma, tais como altura, velocidade e inclinação (INPE, 2019).

Para a elaboração dos mapas utilizou-se a metodologia da USGS (2019) para pré-processamento das imagens - correção atmosférica. As bandas dos instrumentos OLI e TIRS foram convertidas para o topo da atmosfera (TOA), em radiância espectral, usando os elementos de brilho redimensionado fornecidos no arquivo de metadados. A banda OLI também foi convertida para TOA reflectância planetária através dos coeficientes de reflectância redimensionado, fornecidos no arquivo MTL.

Para o estudo de cobertura vegetal nativa e uso da terra utilizou-se do método de classificação Bhattacharya implementada no software Spring. Para a definição das classes foi feita uma adaptação, considerando o porte de cobertura vegetal do sistema básico de classificação da cobertura e do uso da terra - SCUT do IBGE. Após essa adaptação e com base em interpretação visual foram definidas quatro classes diferentes, demonstradas 
a seguir: áreas urbanizadas (vilas, cidades ou complexos industriais); áreas descobertas (sem nenhum tipo de vegetação ou com solo totalmente exposto); vegetação campestre (vegetação rasteira, gramíneas, árvore de pequeno porte ou vegetação dispersa e falha); vegetação florestal (áreas com formações arbóreas e florestas densas).

\section{A fauna do Aeroporto}

Para identificar elementos da fauna presentes na área do aeroporto de Palmas e avaliar possíveis impactos, foram obtidos os registros com a estimativa de colisões, de quase-colisões e de avistamento de fauna, do Centro de Investigação e Prevenção de Acidentes Aeronáuticos - CENIPA (CENIPA, 2019), para os anos de 2014, 2016 e 2018.

A colisão é um evento registrado quando: a tripulação testemunha colisão entre avião e fauna; há evidência ou dano decorrente de colisão identificado em aeronave; há carcaça de animal localizada em até 50 metros das laterais da pista de pouso e de táxi, ou a 300 metros das cabeceiras de pista de pouso; ou há presença de fauna no aeródromo ou fora dele, e exerce efeito significativo sobre a operação de aeronaves (ex.: abortiva de decolagem, etc.). A quase-colisão é registrada quando existe uma colisão evitada pelo desvio realizado pelo animal ou pela tripulação. Já o avistamento ocorre quando um animal vivo é visualizado nas proximidades da trajetória da aeronave, sem ter sido necessário o desvio do animal, ou pela tripulação (CENIPA, 2019).

Também foram analisados os registros de encontro com animais, nos documentos do aeroporto de Palmas, para os anos em estudo. A busca ativa, com registro de imagem dos animais, foi realizada em 14 horas, dentro de 7 dias do mês de julho de 2017, entre os períodos matutinos e vespertinos. A identificação das espécies foi realizada por duas biólogas da INFRAERO e por um biólogo da UFT. As imagens foram obtidas nas áreas do estacionamento e na fachada do aeroporto.

\section{Resultados e discussões}

\section{Análise da vegetação por sensoriamento remoto}

As Figuras 2, 3 e 4 apresentam as imagens de satélite do aeroporto de Palmas para os anos de 2014, 2016 e 2018, respectivamente. Os mapas da área de estudo demonstraram que há predominância da classe de vegetação florestal e campestre no resultado da mensuração de classes, demonstrado no Quadro 1.

Conforme o sistema de classificação adotado pelo IBGE (2013), a vegetação natural compreende um conjunto de estruturas florestais e campestres, abrangendo desde florestais e campos originais (primários) e alterados até formações florestais espontâneas secundárias, arbustivas, herbáceas e/ou gramíneo-lenhosas, em diversos estágios sucessionais de 
desenvolvimento, distribuídos por diferentes ambientes e situações geográficas.

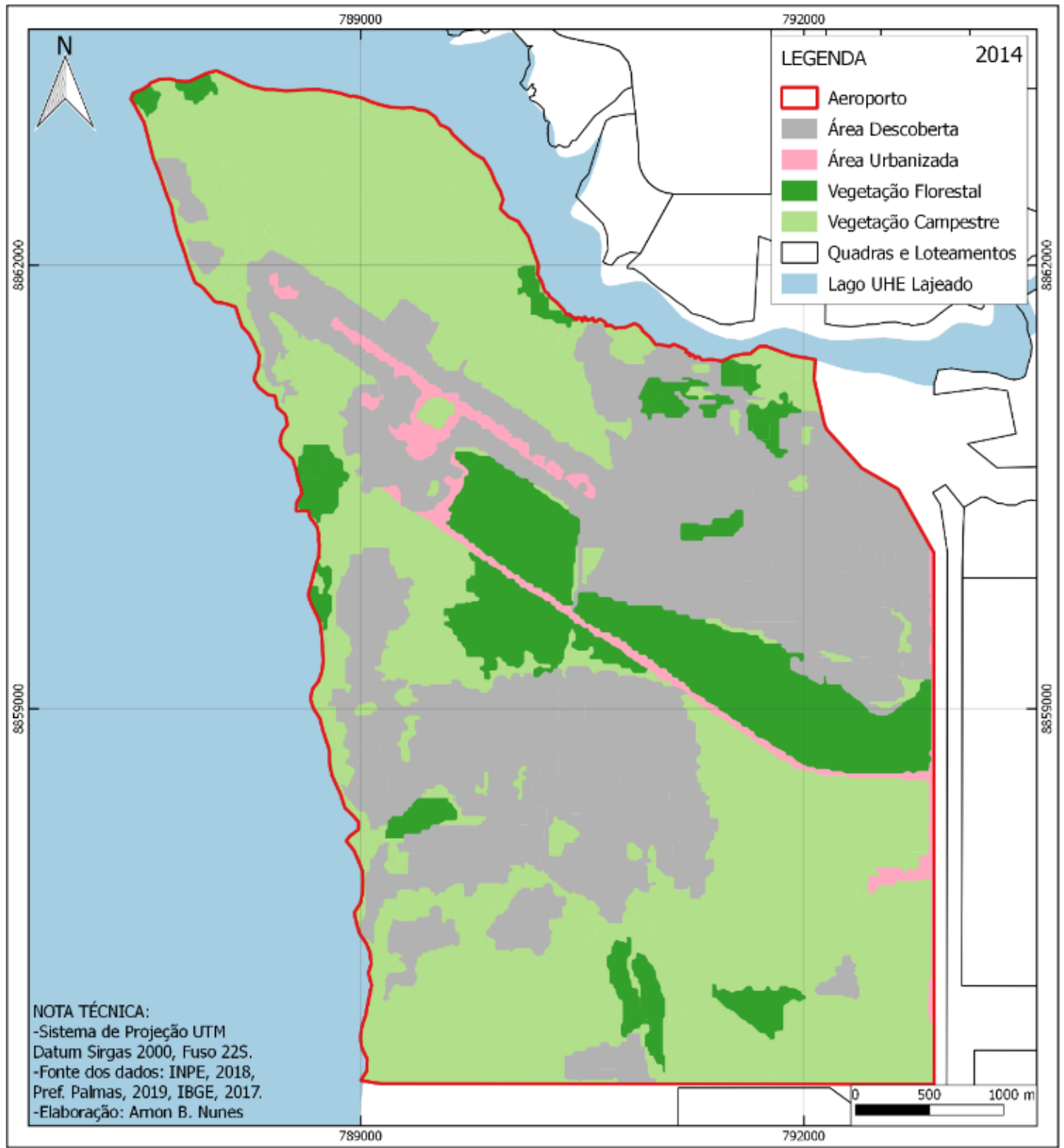

Figura 2: Mapa de cobertura vegetal nativa e uso e ocupação da terra da área patrimonial do aeroporto Brigadeiro Lysias Rodrigues, em Palmas-TO, em 2014.

Figure 2: Map of native vegetation cover and use and occupation of the land of the patrimonial area of the airport of Palmas-TO, in 2014.

Fonte: INPE (2018), Prefeitura de Palmas/TO (2019), IBGE (2017).

Source: INPE (2018), Prefeitura de Palmas/TO (2019), IBGE (2017).

A classe de vegetação campestre, na Classificação das Fitofisionomias do Bioma Cerrado, segundo Ribeiro e Walter (2008), dividese em gradientes fisionômicos que variam de formações campestres, que compreende as espécies herbáceas; formações florestais, com 0 componente arbóreo bem desenvolvido; e formações savânicas, onde o estrato herbáceo-arbustivo é abundante e o estrato arbóreo esparso. $\mathrm{Na}$ 
área de estudo foram verificadas diversas áreas com essa similaridade, principalmente as que compõem o Cerrado Sentido Restrito.

A vegetação campestre ocupou $47,61 \%$ da área patrimonial do aeroporto em 2014, reduzindo para 36,04\% em 2016, com posterior acréscimo em 2018. Concomitantemente a vegetação arbórea passou de 12,94\% em 2014 para 46,20\%, em 2016 (Quadro 1). Os resultados indicam que estas alterações sugerem um bom estado de conservação da área, uma vez que houve um aumento da vegetação florestal (de maior porte), e manutenção da vegetação campestre (de menor porte) foram predominantes em relação as demais classes.

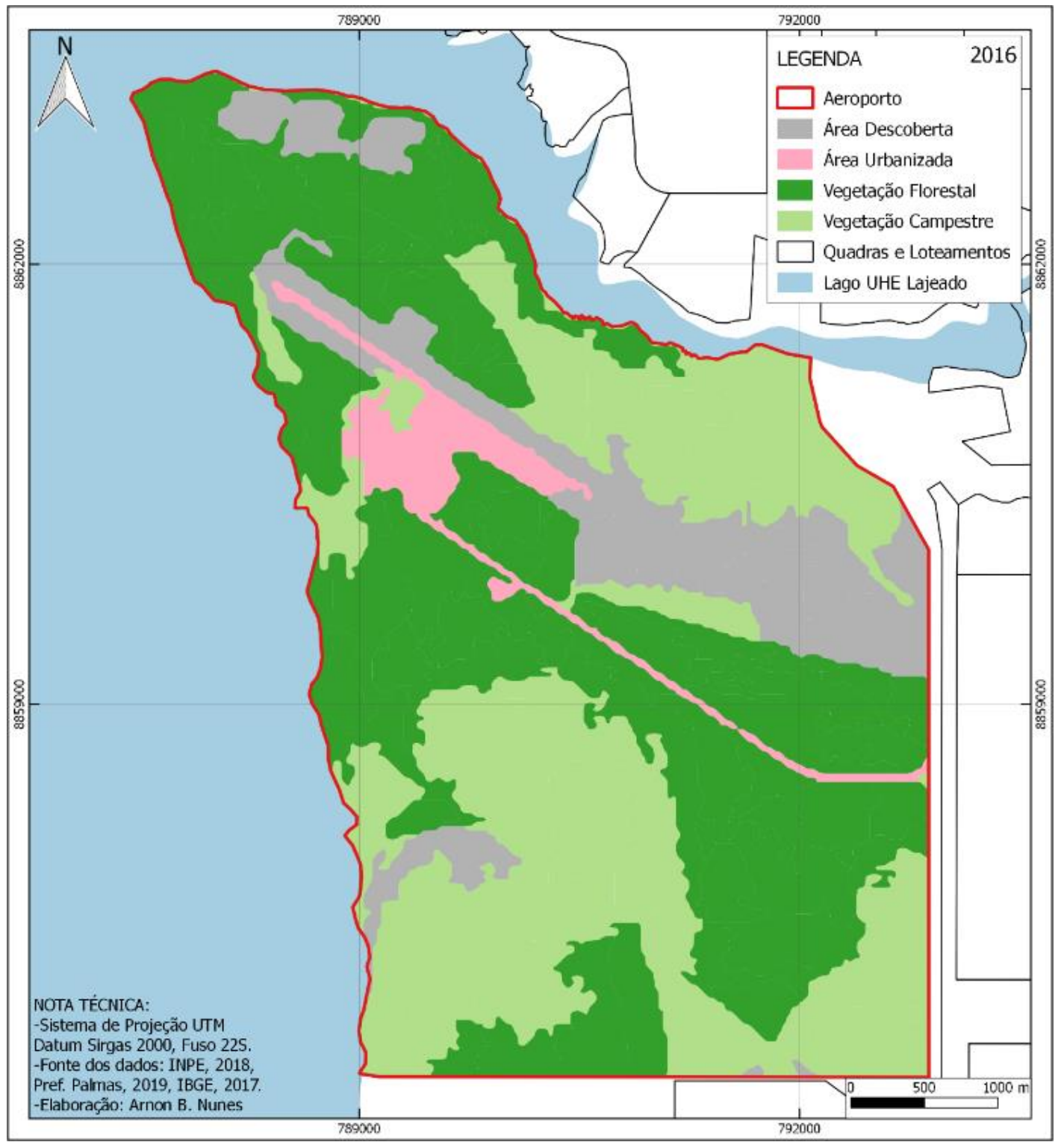


Figura 3: Mapa de cobertura vegetal nativa e uso e ocupação da terra da área do aeroporto Brigadeiro Lysias Rodrigues, em Palmas-TO, em 2016.

Figure 3: Map of native vegetation cover and use and occupation of the land of the patrimonial area of the airport of Palmas-TO, in 2016.

Fonte: INPE (2018), Prefeitura de Palmas/TO (2019), IBGE (2017).

Source: INPE (2018), Prefeitura de Palmas/TO (2019), IBGE (2017).

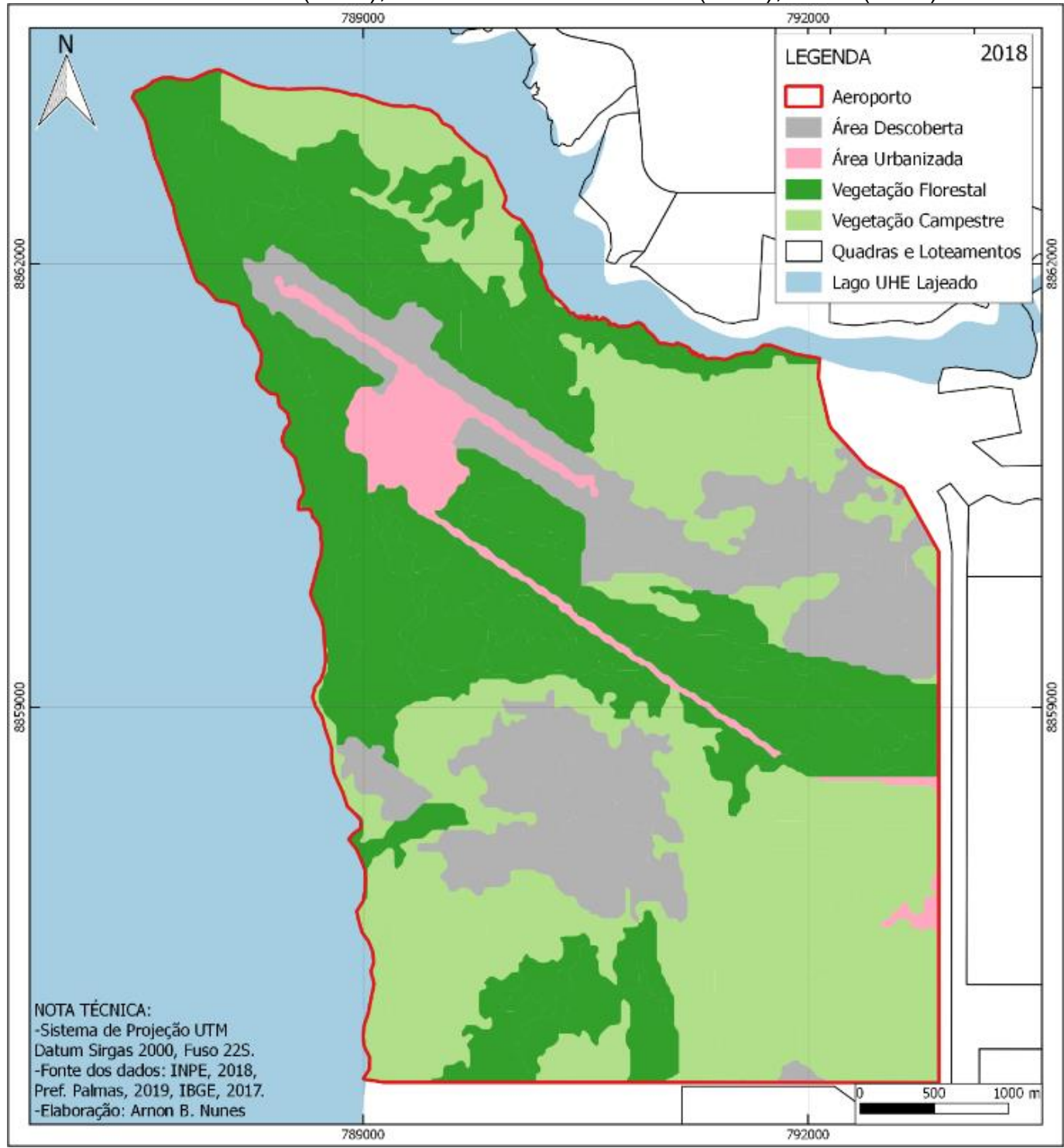

Figura 4: Mapa de cobertura vegetal nativa e uso e ocupação da terra da área do aeroporto Brigadeiro Lysias Rodrigues, em Palmas-TO, em 2018.

Figure 4: Map of native vegetation cover and use and occupation of the land of the patrimonial area of the airport of Palmas-TO, in 2018.

Fonte: INPE (2018), Prefeitura de Palmas/TO (2019), IBGE (2017).

Source: INPE (2018), Prefeitura de Palmas/TO (2019), IBGE (2017).

Para Ribeiro e Walter (2008) as formações florestais possuem porte arbóreo superior a $5 \mathrm{~m}$, incluindo-se as fisionomias da Floresta Densa (estrutura florestal com cobertura superior contínua). Este título inclui áreas remanescentes primárias e estágios evoluídos de recomposição florestal (capoeirões/capoeiras) das diversas regiões fitogeográficas consideradas como florestais): Savana Florestal (Cerradão). 
A vegetação florestal ocupou $12,94 \%$ da área patrimonial do aeroporto em 2014, aumentou para $46,20 \%$ em 2016, e reduziu em 8,54\% a área ocupada no ano de 2018 (Quadro 1). Portanto, a área de vegetação florestal se fez mais presente em 2016 devido ao aumento do porte arbóreo, contudo sofreu alterações em 2018, o que pode estar relacionado, em parte, pela substituição da vegetação florestal pela campestre, que aumentou em $3,38 \%$, e, pelo aumento da área descoberta, que pode ser em decorrência de ações antrópicas, como as queimadas.

Quadro 1: Comparativo do mapa de cobertura vegetal e uso e ocupação da terra do Aeroporto Brigadeiro Lysias Rodrigues/Palmas -TO, nos anos de 2014, 2016 e 2018, por porcentagem $(\mathrm{P})$ e por hectares $(\mathrm{HA})$.

Table 1: Comparison of the vegetation cover map and land use and occupation of the Brigadeiro Lysias Rodrigues / Palmas Airport -TO, in the years 2014, 2016 and 2018, by percentage $(\mathrm{P})$ and by hectares $(\mathrm{HA})$.

\begin{tabular}{|l|r|r|r|r|r|r|}
\hline \multicolumn{1}{|c|}{ Classes } & Ha_2014 & P_2014 & Ha_2016 & P_2016 & Ha_2018 & P_2018 \\
\hline Vegetação Campestre & $1.127,69$ & $47,61 \%$ & 853,50 & $36,04 \%$ & 933,57 & $39,42 \%$ \\
\hline Vegetação Florestal & 306,55 & $12,94 \%$ & $1.094,23$ & $46,20 \%$ & 891,84 & $37,66 \%$ \\
\hline Área Descoberta & 872,57 & $36,84 \%$ & 323,46 & $13,66 \%$ & 449,92 & $19,00 \%$ \\
\hline Área Urbanizada & 61,57 & $2,60 \%$ & 97,18 & $4,10 \%$ & 93,04 & $3,93 \%$ \\
\hline Área total das classes & $2.368,37$ & $100,00 \%$ & $2.368,37$ & $100,00 \%$ & $2.368,37$ & $100,00 \%$ \\
\hline
\end{tabular}

Fonte: Elaborado pelas autoras (2018).

Source: Prepared by the authors (2018).

No que se refere à área específica do aeroporto, a conservação da cobertura vegetal pode ser resultado também das atividades realizadas pela brigada de incêndio voluntária do Aeroporto de Palmas, já que a mesma é responsável por ações preventivas e pelo controle de queimadas na área, e que está cada vez mais eficiente (INFRAERO, 2018).

Portanto, como o aumento das áreas de vegetação campestre e florestal, nos anos em análise, as áreas descobertas diminuíram e as áreas urbanizadas apresentaram pouca variação, ficando em torno de $4 \%$ do solo ocupado. Assim, os resultados demonstram a manutenção da cobertura vegetal nativa da área aeroportuária, o que é favorável à fauna e flora presente no local. Destaca-se que a área se manteve com uma conservação significativa de $60 \%$ de cobertura vegetal em todos os anos estudados.

\section{A fauna do Aeroporto}

A pesquisa documental junto ao CENIPA (2019), para o aeroporto de Palmas, registrou os números de colisão, quase-colisão e avistamento. $O$ maior quantitativo de animais foi registrado por avistamento, 33 animais para 2014, 7 para 2016 e 25 animais para 2018. Nestes anos também foram notificados os maiores registros para colisão, 14 e 15 animais, respectivamente (Quadro 2).

Os registros de colisão, quase-colisão e avistamento podem ser repassados ao CENIPA via formulário próprio por qualquer pessoa da 
comunidade aeroportuária, desde tripulação até passageiros e funcionários. A identificação das espécies da fauna ocorre quase sempre de forma generalista a partir de nomenclatura popular, embora não seja a ideal por não permitir a definição exata do táxon, contudo permite um direcionamento aos grupos vertebrados mais afetados possibilitando planejamento de ações e estratégias de redução de acidentes. Outro fator importante quanto aos registros, sobretudo de colisão, é a impossibilidade de identificação dos animais devido as más condições do corpo do animal após o acidente, com preservação parcial do corpo impossibilitando a diagnose das espécies.

Quadro 2: Registro de colisão, quase colisão e avistamento de animais segundo registro do CENIPA, para o Aeroporto Brigadeiro Lysias Rodrigues/Palmas -TO. Dados coletados para os anos de 2014, 2016 e 2018.

Table 2: Record of collision, near collision and sighting of animals according to CENIPA record, to Brigadeiro Lysias Rodrigues / Palmas Airport -TO. Data collected for the years

\begin{tabular}{|c|c|l|c|c|c|c|}
\hline Ano & Colisão & \multicolumn{1}{|c|}{ Animal } & $\begin{array}{l}\text { Quase } \\
\text { colisão }\end{array}$ & Animal & $\begin{array}{l}\text { Avista- } \\
\text { mento }\end{array}$ & \multicolumn{1}{c|}{ Animal } \\
\hline 2014 & 14 & $\begin{array}{l}\text { pombo; morcego; } \\
\text { mamíferos } \\
\text { menores de } \\
1,5 \mathrm{~kg}, \text { a maioria } \\
\text { não identificados }\end{array}$ & 0 & - & 33 & $\begin{array}{l}\text { Seriema, urubu, quero- } \\
\text { quero, gavião, } \\
\text { curicacas, outros } \\
\text { mamíferos menores de } \\
1,5 \mathrm{~kg} \text {, serpente, } \\
\text { cachorro selvagem }\end{array}$ \\
\hline 2016 & 10 & $\begin{array}{l}\text { rolinha, os demais } \\
\text { não foram } \\
\text { identificados }\end{array}$ & 3 & urubu & 7 & $\begin{array}{l}\text { carcará, urubu, não } \\
\text { identificados }\end{array}$ \\
\hline 2018 & 15 & $\begin{array}{l}\text { urubu, os demais } \\
\text { não foram } \\
\text { identificados, }\end{array}$ & 0 & - & 25 & $\begin{array}{l}\text { Seriema, outros } \\
\text { mamíferos menores de } \\
1,5 \mathrm{~kg}, \text { não identificados }\end{array}$ \\
\hline
\end{tabular}

Fonte: CENIPA (2019). Source: CENIPA (2019).

Um estudo acerca de colisões entre aeronaves e aves realizado em 10 aeroportos do Nordeste do Brasil, entre os anos de 1985 a 2009, demonstrou percentual de $44 \%$ da fauna não identificada nos registros do CENIPA (GALVÃO; ALVAREZ, 2010). Nesse sentido, faz-se necessário incentivar 0 conhecimento das espécies junto aos profissionais aeroportuários, pilotos, dentre outros, para que possam reportar as ocorrências de forma mais completa e contribuir para as pesquisas.

Nos registros do aeroporto foram notificados o encontro de animais silvestres e domésticos, dos mais variados grupos de vertebrados, tais como: sapo (anfíbios); andorinha, anu-branco, anu-preto, arara-canindé, bem-te-vi, canário, carcará, coruja, corucão, ema, joão-de-barro, galinhad'água, garça, pato, periquito, pica-pau, pombo, quero-quero, sabiá, seriema, urubu, jacú, primavera, gavião-carrapateiro, tesourinha, jacupemba, graúna, fogo-apagou, papagaio-verdadeiro (aves); cachorro, capivara, cavalo, cutia, gato, gato-do-mato, jaguatirica, lobo, macaco, preá, raposinhado-campo, rato, tamanduá, tatu, veado (mamíferos); camaleão, cobra, iguana, jabuti (répteis). Além destes, os registros no CENIPA relatam rolinha e gavião (ave), serpente (réptil), morcego (mamífero) (Quadro 2). 
Dentre os animais identificados, alguns constam nas listas da fauna ameaçada de extinção, como o lobo-guará e o tamanduá-bandeira (MMA 2014, IUCN 2019), sendo necessário maior atenção quanto à sua conservação.

Com a busca ativa foi possível identificar sete espécies de aves, um réptil e um mamífero (Quadro 3). Contudo, como os registros fotográficos foram realizados nas áreas de maior circulação de pessoas, tais como, estacionamento e área da fachada do aeroporto. É importante destacar a necessidade de ampliar a área de busca para identificar os animais que habitam, principalmente, as áreas de vegetação florestal e campestre, que foram as áreas de maior representatividade no aeroporto de Palmas, para incrementar a listagem obtida.

Quadro 3: Animais avistados por busca ativa no sítio aeroportuário, Aeroporto Brigadeiro Lysias Rodrigues/Palmas -TO.

Table 3: Animals sighted by active search at the airport site, Brigadeiro Lysias Rodrigues /

\begin{tabular}{|l|l|l|}
\hline \multicolumn{2}{|c|}{ Palmas Airport -TO. } \\
\hline $\begin{array}{l}\text { Pássaro-preto } \\
\text { ou graúna }\end{array}$ & Nome científico & Registro fotográfico \\
\hline $\begin{array}{l}\text { Coruja- } \\
\text { buraqueira }\end{array}$ & Athene cunicularia & \\
\hline Quero-quero & Vanellus chilensis & \\
\hline $\begin{array}{l}\text { Pica-pau } \\
\text { campo do }\end{array}$ & Colaptes campestris \\
\hline Carcará & Caracara plancus & \\
\hline Anu-branco & Guira guira & \\
\hline $\begin{array}{l}\text { Cobra } \\
\text { pinto }\end{array}$ & Drymarchon corais & \\
\hline $\begin{array}{l}\text { Cardeal-do- } \\
\text { nordeste }\end{array}$ & Paroara dominicana \\
\hline Mico-estrela & Callithrix penicillata \\
\hline
\end{tabular}

Fonte: Elaborado pelas autoras (2018).

Source: Prepared by the authors (2018). 
A cobra papa-pinto (Drymarchon corais) e o mico-estrela (Callithrix penicillata), registrados no quadro 3 , foram atropelados na rodovia que dá acesso ao aeroporto. Os animais mortos geralmente são recolhidos pelo setor de Segurança do Aeroporto para que não atraiam outros animais, em especial os urubus, que aumentam o perigo ao trânsito das aeronaves e de veículos automotores. A presença do urubu nas intermediações aeroportuárias é registrada em vários trabalhos e tem sido considerado de alto risco, devido a possibilidade de colisão do animal com as aeronaves, assim como o carcará e o quero-quero (GUEDES, et al., 2010; RUIZESPARZA, et al. 2014).

Os resultados desse trabalho corroboram com outros relatos da literatura em relação à avifauna encontrada em áreas aeroportuárias. Algumas mudanças ambientais consequente de transformações antrópicas se tornam atrativas às aves, como a carcaça de animais, manejo de canteiros, o lixo exposto, etc. Situações que precisam ser levadas em consideração pelos administradores, a fim de minimizar estes impactos (DONATO, 2008; GARRAFA et al., 2009; GUEDES et al., 2010; SOUZA; GOMES; CARVALHO, 2016).

As características ambientais locais também são atrativas aos vertebrados. Conforme registro em documentos do aeroporto, no sítio aeroportuário há árvores frutíferas que atraem a fauna, como pequizeiro, mangabeira, mangueira, cajueiro, puçazeiro. Atividades de observação de aves em áreas limítrofes junto a Praia do Buriti mostraram a ocorrência de espécies de aves típicas do bioma Cerrado, (mineirinho - Charitospiza eucosma; suiriri-da-chapada - Suiriri affinis - T. Dornas obs. pessoal) e outras até então não registradas nos limites de Palmas como o beija-florametista (Calliphlox amethystina) e o guaracava-modesta (Sublegatus modestus) (BARBOSA et al., 2015), as quais potencialmente indicam o valor de conservação da área com relação ao município de Palmas e seu plano diretor.

Existem alguns valores e benefícios associados à existência de áreas urbanas protegidas, como a proteção de uma parte do ecossistema, maior permeabilização do solo, diminuição de ruído, de poluição, da temperatura climática, maior interação social, fomento para a educação ambiental, dentre outros (GOMES; SOARES 2003; COSTA; COSTA, 2011; PELLIN et al., 2014; CARVALHO; GOSLING, 2019). Newman (2014) corrobora ao reforçar a importância da cidade que insere a natureza, por meio do paisagismo, dentro e fora dos edifícios, em paredes, estradas e de sua infraestrutura verde urbana, de forma a estabelecer a natureza em todos os elementos do ambiente construído. Os espaços verdes resgatam o contato da espécie humana com a natureza, ao enfatizar a presença de características verdes, formas de vida e processos com os quais o homem possui afinidade (BEATLEY; NEWMAN, 2013).

Neste contexto, ainda que Palmas seja uma capital jovem, existe uma tendência da sociedade contemporânea e capitalista, em se desconectar com a natureza, o que reforça a necessidade de rever como as 
comunidades e cidades devem ser planejadas e redesenhadas, servindo de base para um novo modelo, que faça uso de um planejamento urbano criativo, o qual torne a natureza a peça central, não em uma reflexão tardia (BEATLEY, 2011). Esse planejamento deve contemplar áreas de conservação que possam garantir a manutenção da fauna e flora local, e também servir de espaços biofílicos voltados ao ecoturismo.

\section{Considerações finais}

Neste estudo constatou-se que a área do Aeroporto de Palmas vem sendo conservada nos últimos anos, o que se mostra bastante favorável à flora e fauna locais. As formações florestais e campestres somadas apresentaram aumento em suas áreas, o que indica um bom estado de conservação da área patrimonial.

Quanto à fauna, a maioria das espécies identificadas por meio de buscas em fontes secundárias e relatório CENIPA representam espécies comuns, com ampla distribuição, da fauna nativa do Cerrado e do Brasil. No entanto, espécies de aves como mineirinho, suiriri-da-chapada, beija-florametista e o guaracava-modesta, avistadas em áreas de vegetação nativa, afastadas da área operacional, juntamente com registros de lobo-guará e tamanduá-bandeira refletem a existência de uma diversidade de espécies ainda maior, com espécies carentes de ações de conservação. Estudos de inventariamento da fauna nas áreas naturais da área patrimonial, portanto são altamente desejáveis.

Por outro lado, deve-se considerar que a antropização interfere no equilíbrio destas populações animais que podem culminar em uma série de ameaçadas, sendo os riscos de acidentes com as aeronaves potencialmente as mais graves. Os impactos gerados à fauna, sobretudo em relação às aves, se dão em razão de colisões com aeronaves. Para os demais vertebrados o atropelamento, na via de acesso ao aeroporto, e as queimadas são os fatores que devem ser considerados.

Por fim, é importante reforçar que a área patrimonial do aeroporto de Palmas representa um importante remanescente da vegetação nativa do bioma Cerrado, em especial como contrapartida ao processo de urbanização local dos últimos 30 anos, com fauna e flora bastante características. Essa área está inserida na área urbana da cidade, e permite a manutenção de serviços ecológicos e ecossistêmicos locais, portanto, conservá-la é uma importante estratégia em âmbito regional.

Deste modo, esta área tem um potencial enorme para atividades de ecoturismo, de modo que uma alternativa bastante promissora seria a criação de um complexo público de ecoturístico, que reuniria parte sul da área patrimonial do aeroporto e a área da Praia do Buriti, local de lazer de responsabilidade do poder municipal, resultando de fato em uma ação de caráter sustentável pois possibilitará conexão da população com este 
ambiente natural concomitantemente a conservação da flora e fauna e demais elementos da biodiversidade locais.

\section{Referências}

BEATLEY, T. Biophilic Cities: Integrating Nature into Urban Design and Planning. Washington, DC: Island Press, 2011.

BEATLEY, T; NEWMAN, P. Biophilic Cities Are Sustainable, Resilient Cities. Sustainability, Suíça. v. 5, n. 8, p. 3328-3345, 2013. Disponível em: <http://www.mdpi.com/2071-1050/5/8/3328/htm>. Acesso em: 13 mai. $\underline{2017}$

CARVALHO, IB; GOSLING, MS. Percepções e experiências do usuário no Parque Municipal de Belo Horizonte: estrutura, uso e manutenção. Revista Brasileira de Ecoturismo, v.12, n.1, p.101-121, 2019. Disponível em: $<$ https://periodicos.unifesp.br/index.php/ecoturismo/article/view/6665>.

Acesso em: 20 março. 2019

CENTRO DE INVESTIGAÇÃO E PREVENÇÃO DE ACIDENTES AERONÁUTICOS - CENIPA. Sistema de Gerenciamento de Risco Aviário. Disponível em: <http://www.cenipa.aer.mil.br/cenipa/index.php/ estatisticas/estatisticas/risco-da-fauna>. Acesso em: 13 jan. 2019.

CHACEL, F. M. Paisagismo e ecogênese. Rio de Janeiro: Fraiha, 2001.

CONSELHO NACIONAL DO MEIO AMBIENTE - CONAMA. Resolução no 01, de 23 de janeiro de 1986. Dispõe sobre critérios básicos e diretrizes gerais para o Relatório de Impacto Ambiental - RIMA. Disponível em: <http://www.mma.gov.br/port/conama/legiabre.cfm?codlegi=23>. Acesso em: 20 set. 2018.

COSTA, NMC; COSTA, VC. Da escola à natureza: uma experiência de Educação Ambiental em área protegida na cidade do Rio de Janeiro. Interagir: pensando a extensão, n. 16, p. 65-69, 2011. Disponível em: $<$ https://www.e-publicacoes.uerj.br/index.php/interagir/article/view/5327>.

Acesso em: 20 fev. 2019.

GALVÃO, WN; ALVAREZ, MRDV. O perigo aviário em aeroportos do nordeste do Brasil: Análise das colisões entre aves e aviões entre os anos de 1985 e 2009. Revista Conexão Sipaer, v. 1, n. 3, p. 47-68, 2010. Disponível em: http://conexaosipaer.cenipa.gov.br/index.php/sipaer/article/ viewFile/43/77. Acesso em: 13 fev. 2019.

GARAFFA, PI; FILLOYA, BM; BELLOCQ, I. Bird community responses along urban-rural gradients: does the size of the urbanized area matter? Landscape and Urban Planning, v. 90, p. 33-41, 2009. Disponível em:< https://doi.org/10.1016/j.landurbplan.2008.10.004>. Acesso em: 11 fev. 2019. 
GOMES, MAS; SOARES, BR. Vegetação nos centros urbanos: considerações sobre os espaços verdes em cidades médias brasileiras. Estudos Geográficos, v.1, n.1, p.19-29, 2003. Disponível em: < http://www.redbcm.com.br/arquivos/bibliografia/a\%20vegeta\%C3\%A7\%C3\% A30\%20nos\%20centros\%20urbanos.pdf>. Acesso em: 11 fev. 2019.

GUEDES, FL; BRAND, H; LINHARES, BP; PAIVA, LV. Avifauna relacionada ao risco de colisões aéreas no aeroporto internacional Presidente Juscelino Kubitschek, Brasília, Distrito Federal, Brasil. Revista Conexão Sipaer, v. 2, n. 1, p. 230-243, 2010. Disponível em:< http://conexaosipaer.cenipa.gov.br/ index.php/sipaer/article/view/57>. Acesso em: 20 fev. 2019.

HAUPTFLEISCH, ML; AVENANT, NL. Integrating small mammal community variables into aircraft-wildlife collision management plans at Namibian airports. Integrative zoology, n. 10, p. 515-30, 2015. Disponível em: <https://onlinelibrary.wiley.com/doi/full/10.1111/1749-4877.12160>. Acesso em: 13 fev. 2019.

HERZOG, CP. Cidades para todos: (re)aprendendo a conviver com a natureza. 1. ed. - Rio de Janeiro: Mauad X: Inverde, 2013. 312 p.: il.

INFRAESTRUTURA AEROPORTUÁRIA - INFRAERO. Meio Ambiente. Disponível em: < http://www.INFRAERO.gov.br/ >. Acesso em: 28 set. 2018.

INSTITUTO BRASILEIRO DE GEOGRAFIA E ESTATÍSTICA - IBGE. Fauna ameaçada de extinção. Disponível em: < https://mapas.ibge.gov.br/ tematicos/fauna-ameacada-de-extincao.html>. Acesso em: 20 jan. 2018.

INSTITUTO BRASILEIRO DE GEOGRAFIA E ESTATÍSTICA - IBGE. Mapa da Amazônia Legal. Disponível em: < http://www.ibge.gov.br/home/ geociencias/geografia/amazonialegal.shtm?c=2>. Acesso em: 16 jan. 2017.

INSTITUTO BRASILEIRO DE GEOGRAFIA E ESTATÍSTICA-IBGE, Manual Técnico de uso da Terra. 3. ed. Rio de Janeiro: IBGE, 2013. 171 p. (Manuais técnicos em Geociências, n. 7).

INSTITUTO NACIONAL DE PESQUISAS ESPACIAIS -INPE. Imagens provenientes do Landsat 8 Instrumento Sensor Operative Land Imager (OLI): Divisão de Geração de Imagens (DIDGI). Imagens. Dimensões: 170x183km. Disponível em:<http://www.dgi.inpe.br/catalogo/>. Acesso em: 25 mar. 2019.

IUCN 2019. The IUCN Red List of Threatened Species. Version 2019-1. Disponível em:<https://www.iucnredlist.org > . Acesso em: 20 março 2019.

LEITE, C. Cidades sustentáveis, cidades inteligentes: desenvolvimento sustentável num planeta urbano./ Carlos Leite, Juliana di Cesare Marques Awad. - Porto Alegre: Bookman, 2012.

MMA - Ministério do Meio Ambiente. 2014. Lista Nacional Oficial de Espécies da Fauna Ameaçadas de Extinção. Portaria No - 444, 17 De Dezembro de 2014. Diário Oficial da União, 17 de dezembro de 2014. Disponível em: <http://www.icmbio.gov.br>. Acesso em: 20 março 2019. 
M.O. Barbosa, Dornas, T., Dionísio, C. \& D. G. Marcelino 2015. Novos registros ornitológicos para a região de Palmas, Tocantins. Atualidades Ornitológicas, $\quad$ v. 188, p. 59-65. Disponível em: $<$ http://www.ao.com.br/download/A0188 59.pdf>. Acesso em: 20 março 2019.

MINISTÉRIO DO MEIO AMBIENTE - MMA. Amazônia. Disponível em: <http://www.mma.gov.br/biomas/amaz\%C3\%B4nia>. Acesso: 16 jan. 2016.

NASA. The Landsat Program. Disponível em: <http://landsat.gsfc.nasa.gov/> Acesso em: 20 jan. 2019.

PELLIN, A; CARVALHO, G; REIS, JC; PELLIN, A. Gestão do uso público em unidades de conservação urbanas: 0 caso do Parque Estadual da Pedra Branca (RJ). Revista Brasileira de Ecoturismo, v.7, n.2, p. 344-373, 2014. Disponível em: < https://periodicos.unifesp.br/ index.php/ecoturismo/article/view/6368> Acesso em: 16 jan. 2019.

RIBEIRO, JF; WALTER, BMT. As principais fitofisionomias do Bioma Cerrado. In: SANO, S.M.; ALMEIDA, S.P.; RIBEIRO, J.F. (eds). Cerrado: ecologia e flora. Embrapa Cerrado/Embrapa Informação Tecnológica, $2^{a}$ ed, 2008, p.151-212.

RUIZ-ESPARZA, J, CONCEIÇÃO, AM, SILVA, C, SANTOS, MAHA, TAVARES, DS. Avaliação do Perigo de Fauna no Aeroporto de Aracaju Santa Maria, Sergipe: Bases para Mitigação do Risco de Colisões com Fauna. Revista Conexão Sipaer, v. 5, n. 1, p. 30-42, 2014. Disponível em: < http://conexaosipaer.cenipa.gov.br/index.php/sipaer/article/view/277>.

Acesso em: 30 jan. 2019.

SACHS, I. Caminhos para o desenvolvimento sustentável. 3 ed. Rio de Janeiro: Ed. Garamond, 2009.

SILVA, CL. Estudo dos impactos das atividades aeroportuárias utilizando dados de sensoriamento remoto. 2014. 98 f., il. Dissertação (Mestrado em Ciências Florestais) - Universidade de Brasília, Brasília, 2014. Disponível em: <http://repositorio.unb.br/handle/10482/17311>. Acesso em: 12 fev. 2019.

SOUSA, ENA; LIMA, RS; ALBUQUERQUE, HN. Inventário preliminar da avifauna do aeroporto Presidente João Suassuna - Campina Grande-PB. Revista Brasileira de Informações Científicas. v.2, n.3, p.60-65, 2011.

SOUZA, AHN, GOMES, HB, CARVALHO, CEA. Corte de grama e monitoramento de fauna para aeroportos brasileiros: uma proposta metodológica. Revista Conexão Sipaer, v. 7, n. 1, p. 96-102, 2016. Disponível em: <http://conexaosipaer.cenipa.gov.br/index.php/sipaer/ article/view/389>. Acesso em: 20 mar. 2019.

UNITED STATES GEOLOGICAL SURVEY - USGS. Conversion to TOA Radiance. Landsat Missions. Disponível em:<https://earthexplorer.usgs.gov/>. Acesso em: 24 mar. 2019.

WILSON, EO. Biophilia. Harvard University Press. 1986. 176pp. 


\section{Nota:}

${ }^{1}$ Os fatores geológicos, biológicos e físicos de um ambiente, considerados nas suas ações conjuntas (CHACEL, 2001).

Mariana Carla de Almeida: Universidade Federal do Tocantins, Palmas, TO, Brasil

E-mail: marianacarlaa@gmail.com

Link para o currículo Lattes: http://lattes.cnpq.br/3876635370269847

Kellen Lagares Ferreira Silva: Universidade Federal do Tocantins, Porto Nacional, TO, Brasil

E-mail: lagares@mail.uft.edu.br

Link para o currículo Lattes: http://lattes.cnpq.br/9200174067176129

Tulio Dornas: Universidade Federal do Tocantins, Palmas, TO, Brasil

E-mail: tuliodornas@yahoo.com.br

Link para o currículo Lattes: http://lattes.cnpq.br/0429327000670110

Fernanda Brito de Abreu: Centro Universitário Luterano de Palmas, Palmas, TO, Brasil

E-mail: fernanda.abreu@mail.uft.edu.br

Link para o currículo Lattes: http://lattes.cnpq.br/1162503005421727

Carla Simone Seibert: Universidade Federal do Tocantins, Porto Nacional, TO, Brasil

E-mail: carlaseibert@yahoo.com

Link para o currículo Lattes: http://lattes.cnpq.br/6679543572745031

Data de submissão: 09 de abril de 2019

Data de recebimento de correções: 16 de abril de 2019

Data do aceite: 16 de abril de 2019

Avaliado anonimamente 